\title{
Prediction of Flowability, Compressive and Flexural Strength on Self-Compacting Concrete Using Fuzzy Logic
}

\author{
Hakas Prayuda $^{1}$, Fanny Monika $^{1 *}$, Fadillawaty Saleh $^{1}$, Pradipta Kumara Prabandaru ${ }^{1}$, \\ Jheval Senna Emerald ${ }^{1}$, Nur Ali Maulida ${ }^{1}$ \\ ${ }^{1}$ Department of Civil Engineering, Faculty of Engineering, Universitas Muhammadiyah Yogyakarta, Indonesia \\ *Corresponding author. Email: fanny.monika.2007@ft.umy.ac.id
}

\begin{abstract}
This research discusses the prediction of flowability value, pressure strength and flexural strength on self-compacting concrete using fuzzy logic. Self-compacting concrete is one of the concretes that can compact itself without the need for a vibrator and compactor during the casting process. The flowability level on self-compacting concrete is very important to guarantee that segregation does not occur, and the concrete can flow. Data from laboratory testing results are primary data collected from previous researchers using various types of mix designs. Data input used is in the form of each constituent material such as cement, sand, water, gravel to additives. Through the results of this study, the predicted value of fresh properties is slump flow, T50, V-Funnel, and L-Box. While the other value obtained is the hardened properties of self-compacting concrete in compressive strength and flexural strength when the concrete is 28 days old. Each test has an error value, which varies but not more than $10 \%$. It can be concluded that fuzzy logic can predict the flowability value, compressive strength, and flexural strength on selfcompacting concrete.
\end{abstract}

Keywords-Fuzzy Logic, Self-Compacting Concrete, Flowability, Compressive Strength, Flexural Strength

\section{INTRODUCTION}

Self-compacting concrete was developed in the construction industry in early 1990 and kept developing for the best quality, especially on the fresh properties assessment [1]. Self-compacting concrete can be defined as one of the concretes, which can condense and flow without a compactor or vibrator's help during the casting process [2]. Generally, the constituent material of self-compacting concrete is the same as conventional concrete, but additive material needs to be added to produce a good flow ability level. So, concrete can flow and solidify. There are many advantages of using selfcompacting concrete, such as minimizing vibration noise, reducing the construction time and cost, and facilitating construction that is difficult to compact manually during the casting process [3].

In using concrete as a construction material, mix design is one of the most important things to determine the compressive strength produced by concrete. The development of mix design in self-compacting concrete continues to experience development in 1993. The mix design for self-compacting concrete was designed by researchers from Japan [4], [5], which then continued to grow with various methods [6]-[9]. Some important things in the mix design planning process in self-compacting concrete are the technical strength produced and the fresh properties. The result of fresh properties was influenced by many factors, including the water to binder ratio [10] and the type of superplasticizer [11].

As it develops, self-compacting concrete not only uses conventional materials, several previous studies have been conducted to examine the value of fresh self-compacting concrete values with a variety of materials including fibers [12], [13], Metakaolin [14], recycled concrete aggregates [15]. With various types of materials used, of course, will produce a variety of fresh properties. This study tries to predict the value of fresh properties, compressive strength, and flexural strength of research data that has been done previously using a fuzzy logic program. The predictive value of compressive strength in self-compacting concrete has been done by several methods such as artificial neural networks [16]-[19], Statistical method [20], and Surrogate models [21].

This research will predict the value of flowability consisting of slump flow, T50, V-Funnel, and L-Box when the concrete is in fresh condition, whereas in hardened conditions, it will predict the compressive and flexural strength. The data used in this study are secondary data that has been collected through various previous studies. The data used in the form of the mix design that has been used is the proportion of material consisting of water, cement, fine aggregate, coarse aggregate, and additive material. This analysis will compare the results of laboratory testing with models using fuzzy logic. In addition, the error factor and the relationship between the 
results of laboratory testing with predictive value. This research is expected to produce a program to determine the value of fresh properties and hardened properties with variations in the types of concrete constituent materials in Indonesia.

\section{FUZZY LOGIC}

The fuzzy logic introduced by Professor Lutfi A. Zadeh, a researcher from California University in 1965 at Barkeley, is a solution to essential obscurity in many social science constructs [22]. Fuzzy logic is an appropriate way to map an input space into an output space using IF-THEN rules:

a. The concept of fuzzy logic is very simple and easy to understand,

b. Fuzzy logic has a tolerance for inappropriate data,

c. Fuzzy logic can model non-linear functions which are very complex,

d. Fuzzy logic can build and apply various experiences of experts without having a training process,

e. Fuzzy logic has a close relationship with the daily language, and

f. Fuzzy logic can be used with various conventional control techniques.

Matrix Laboratory ((MATLAB) is a high-level programming language in numerical computing using a matrix basis. Many tools exist in MATLAB, which can help various branches of disciplines because they have functions and commands that are easy to understand. Fig. 1 is a series of fuzzy interface displays to display some desired analysis.

The MATLAB language supports vector operations, which form the basis of data engineering problems. The fuzzy logic toolbox facility in the MATLAB application makes it easy to model a fuzzy system. The ease of availability can maximize the making of fuzzy logic-based programs. Some tools that can be used to create change and conceptualize fuzzy reasoning can be seen below.

a. Fuzzy Inference System (FIS) Editor, a toolbox used to make and edit the input and output in the fuzzy logic system. The way to bring out the Fuzzy Interference System (FIS) Editor by typing "fuzzy" on the command window in MATLAB.

b. Membership Function Editor, a toolbox used to create and edit existing fuzzy membership functions in input and output. By clicking edit, how to bring it up, select the Membership Function in the Fuzzy Interference System (FIS) Editor toolbox, or can by pressing $\mathrm{Ctrl}+2$.

c. Rule Editor, a toolbox that is used to create and edit rules on fuzzy reasoning systems. The rules made will affect the defuzzification process in fuzzy logic. How to bring it up is to click edit, select Rules in the Fuzzy Interference System (FIS) Editor toolbox, or by pressing Ctrl +3 .

d. Rule Viewer, a toolbox used to see the flow of reasoning in fuzzy, includes input variables, a compilation of rules, implication functions, and defuzzification of output assertions. How to bring it up is to click view, select Rules in the Fuzzy Interference System (FIS) Editor toolbox, or by pressing $\mathrm{Ctrl}+5$.

e. Surface Viewer, a toolbox that is used to view the mapping of input variables with output variables. Variables that are determined from the input are 2 variables, while for output, there is only 1 variable. How to bring it up is to click view then select Surface in the Fuzzy Interference System (FIS) Editor toolbox, or you can by pressing $\mathrm{Ctrl}+6$.

\section{EXPERIMENTAL METHOD}

This study will predict the value of flowability, compressive strength, and flexural strength of self-compacting concrete. The flowability tests carried out consisted of slump flow, T50, V-Funnel, L-Box, and J-Ring. Meanwhile, the compressive strength and flexural strength analyzed resulted when the concrete is 28 days old. The predictions results would be compared with the results of the experiment and analyzed the resulting error rate. 


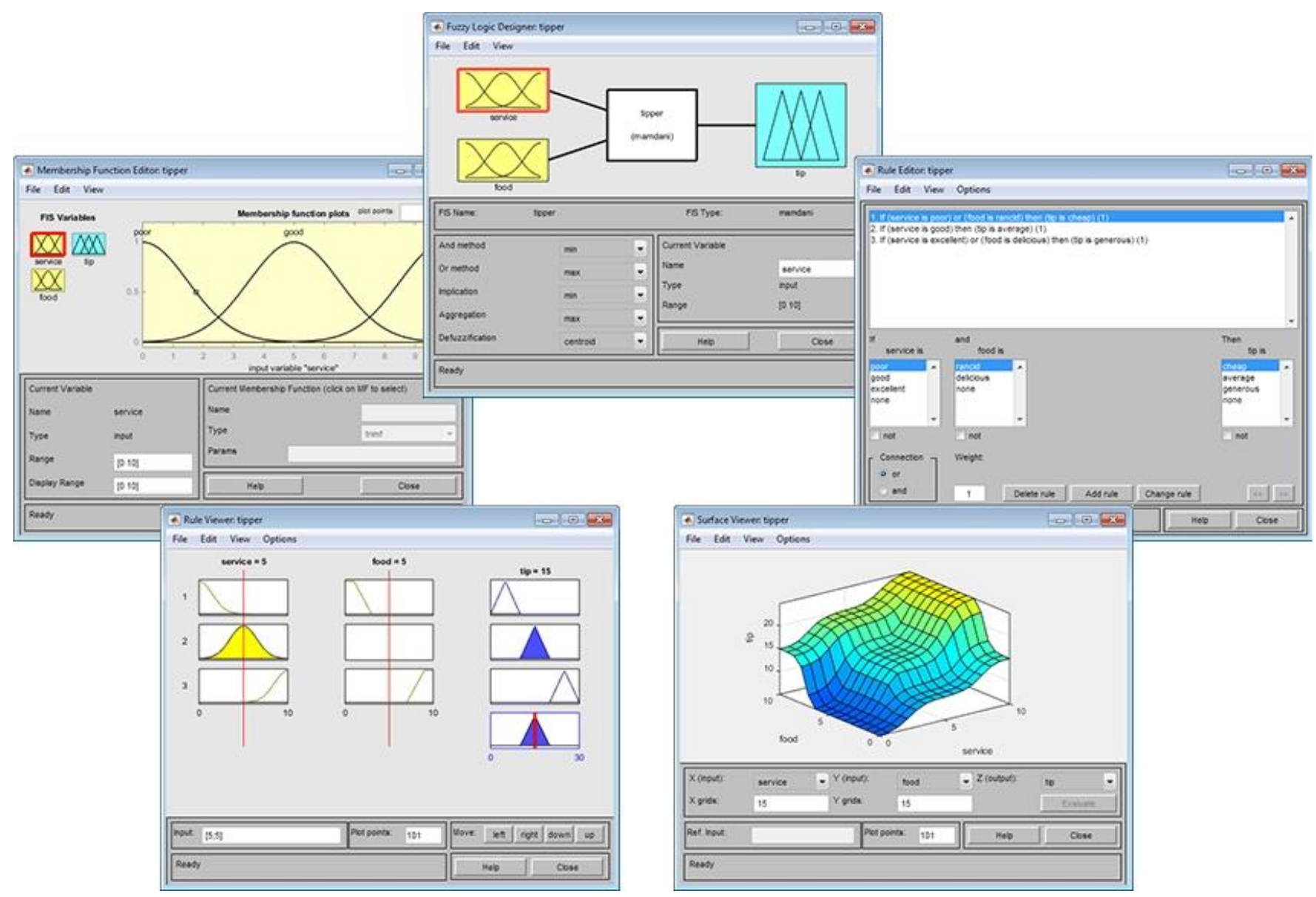

Fig. 1. The display of fuzzy inference system

The membership function was a curve that shows the mapping points indicated by a flat circuit. The membership function in the fuzzy set was used as an approach for each membership value, which was adjusted to the data's characteristics. The fuzzy set was divided into three, namely low, medium, and high. Membership functions in this test were made, as shown in Fig. 2. Membership functions of cement, fly ash, sand, gravel used the functions L, M, and $\mathrm{H}$. Water and superplasticizer used $\mathrm{L}$ and $\mathrm{H}$.

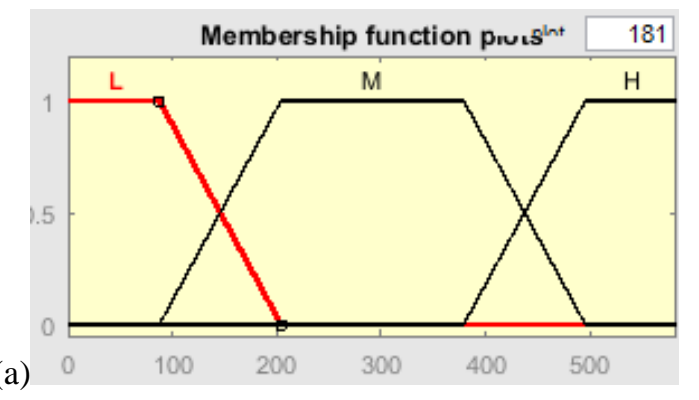

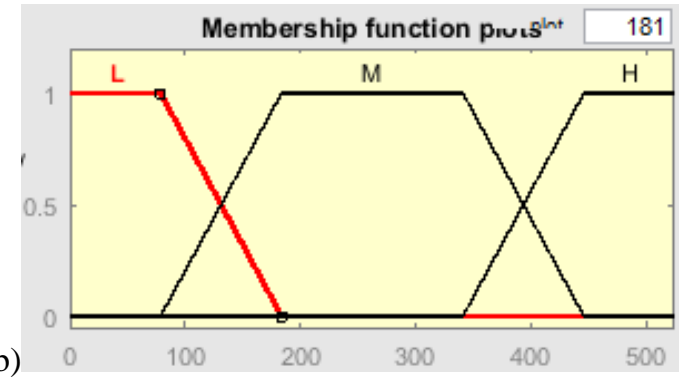

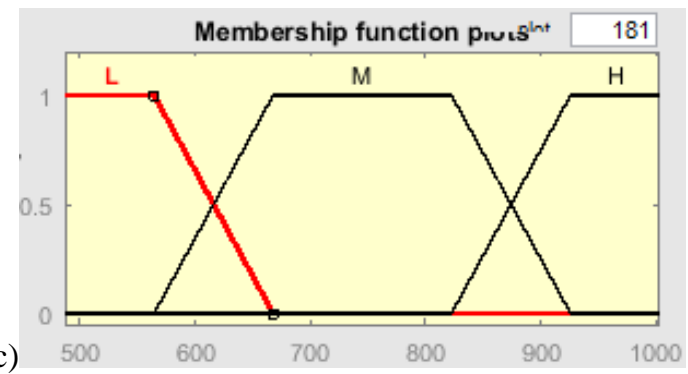




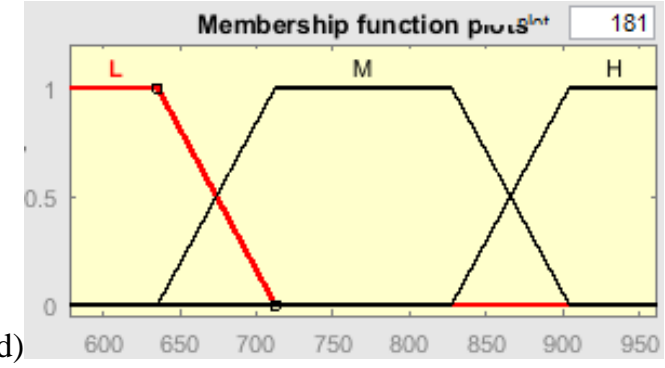

(d)
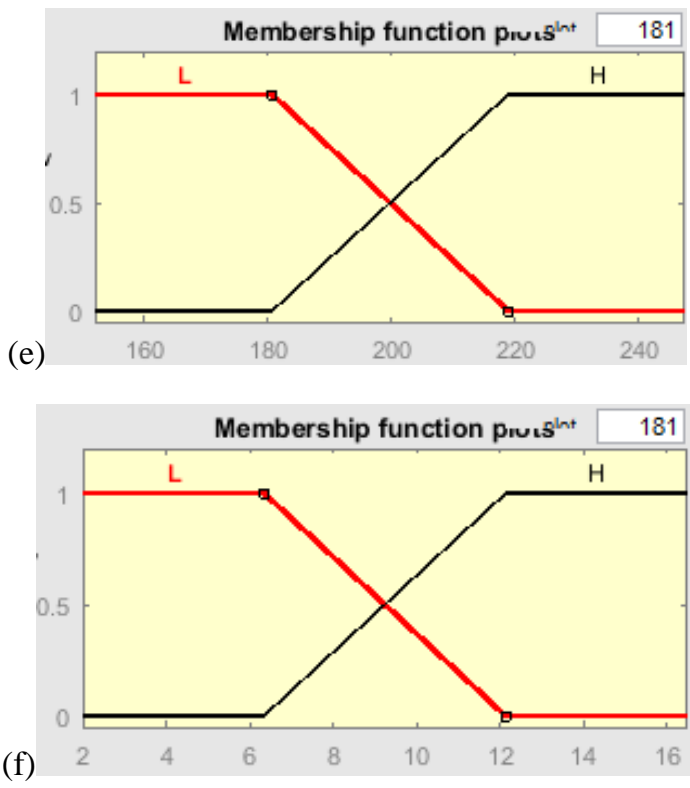

Fig. 2. Membership functions (a) cement (b) fly ash (c) sand (d) gravel (e) water (f) superplasticizer

This study used mixed proportion data that is used by upstream researchers. The material data that were part of this research's input are the amount of cement, fly ash, sand, gravel, water, and superplasticizers. Meanwhile, flexural strength was arranged using the same reinforcement configuration for all test objects so that reinforcement does not affect the analyzed flexural strength.

This study used a Multi-Input Single Output (MISO) system, which uses more than one input variable and only uses one output variable. Rules that work on fuzzy use the statement IF $\mathrm{x}$ is A THEN $\mathrm{y}$ is $\mathrm{B}$. In the overall test, selfcompacting concrete consists of 324 rules that were used

\section{RESULT AND DISCUSSION}

\subsection{Fresh Properties}

Fresh property testing is one of the most important things in self-compacting concrete. Through this test, we will be able to find out the workability value of the concrete. In normal concrete, generally, the value of workability is only measured through slump testing, whereas in self-compacting concrete, several items of fresh property testing are needed to ensure that this concrete can flow without segregation. The value of fresh properties is highly dependent on the mix proportion used, including the amount of cement, water, superplasticizers, and aggregates. In addition, the testing of fresh properties in self-compacting concrete must ensure that fresh concrete can pass obstacles in the compaction process, such as reinforcement and several other obstacles.

Knowing the factors that influence the value of workability can predict the value of fresh properties from self-compacting concrete using the fuzzy method. In Fig. 3, the results of the analysis of fresh concrete fresh properties were compared with the experiments' results. Tests were conducted in this study in slump flow, T50, V-Funnel, L-Box, and J-Ring. The results show no significant difference between the predicted value with the experiment so that, this method can later be used to predict the value of fresh properties that will be generated following the material to be used.

This study also examined the relationship between prediction results and the experimental result conducted by previous researchers. So, these results can be compared with previous experimental results. Figure 4 describes the results of the relationship between the predicted workability values of the experiment. Fig. 4 (a) shows the slump flow relationship against the predicted result and the experimental result. The results show that there are still quite differences between these two results. Meanwhile, the other fresh concrete properties in Fig. 4 have a reasonably good relationship between the experimental result and the predicted result.

The results of each test's workability value, both from the experimental and predictive values, still meet the standards set in using self-computing concrete. Thus, the predicted value of the fresh properties of concrete self-compacting can be applied in the field without the need to make a specimen first. It is intended to reference that the amount of material used can produce a fairly good value of fresh concrete.

The relationship between prediction and experimental values can be known by using linear analysis; then, the difference between experiment and prediction results can also be recognized. Fig. 4 presents the experiment results' value if the predicted value is obtained following the mix proportion that is input into this analysis. Therefore, through this test, it is expected to easily modify the mix proportion according to the needs of the desired fresh properties then, the performance of this self-compacting concrete can run optimally. Fig. 5 explains the error results obtained in analyzing the prediction value of fresh properties using the fuzzy logic method. 
(a)

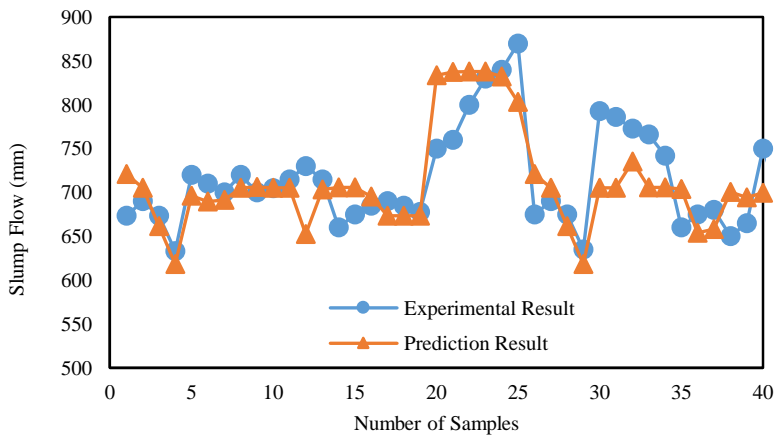

(b)

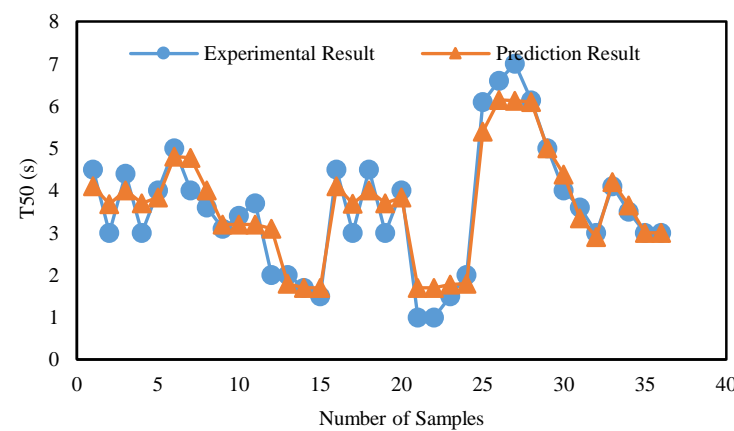

(c)

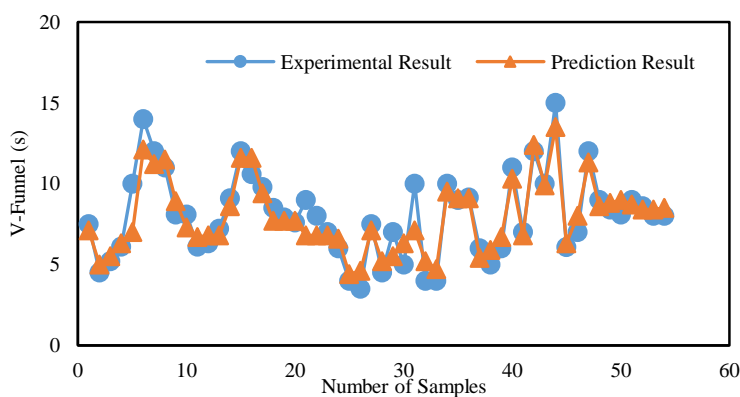

(d)

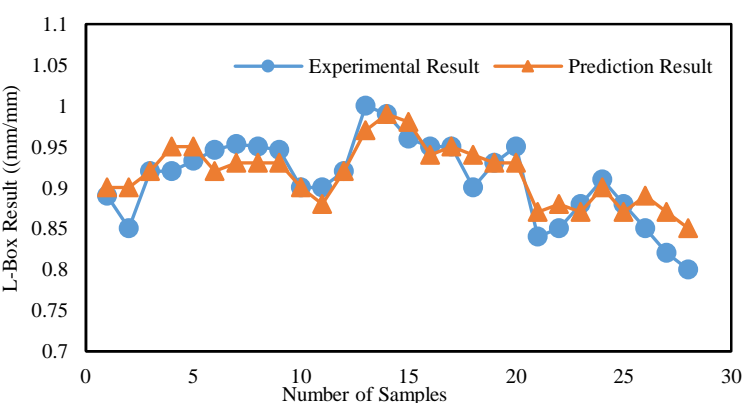

(e)

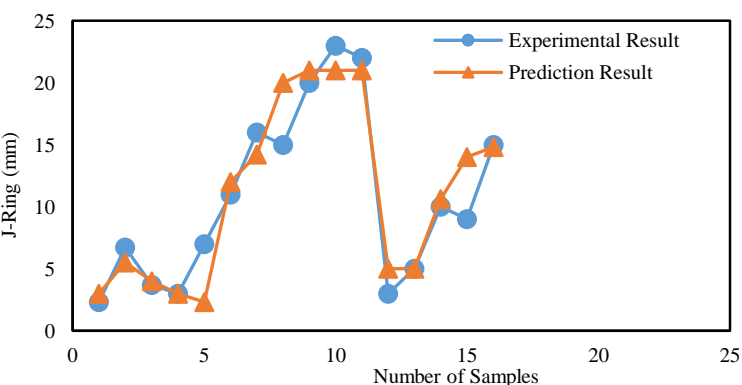

Fig. 3. Fresh Properties Result with different number of samples (a) Slump flow; (b) T50; (c) V-Funnel; (d) LBox; (e) J-ring

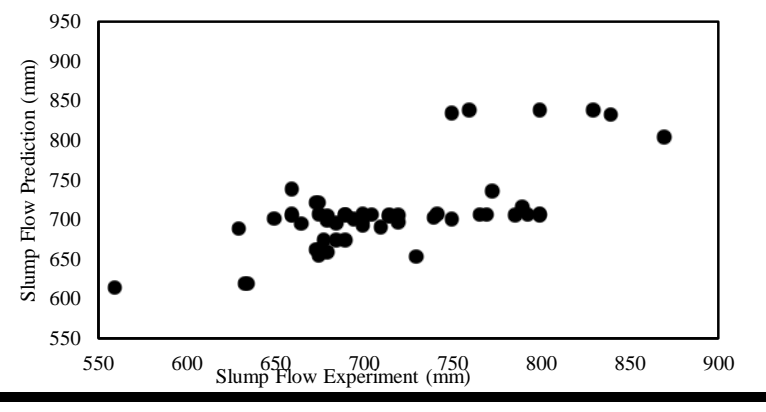

(b)

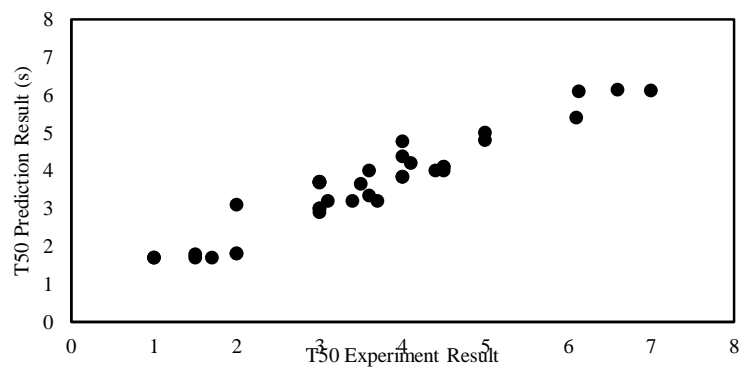

(c)

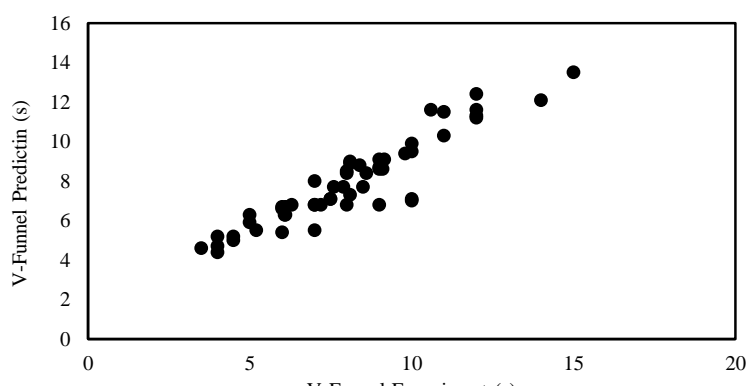

(d)

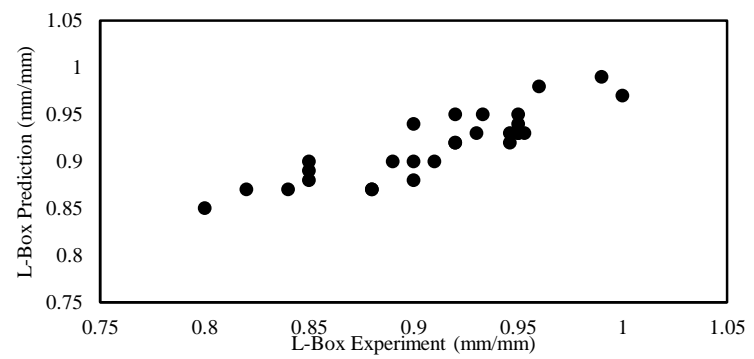

(e)

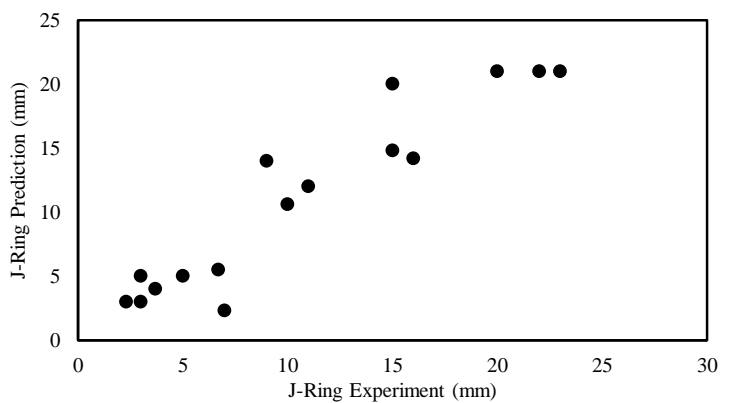

Fig. 4. Relationship between prediction and experiment result (a) Slump flow; (b) T50; (c) V-Funnel; (d) L-Box; (e) J-ring

Fig. 5 (a) presents the error results obtained in slump flow testing. The error is derived from analyzing the difference between the predicted values with the resulting experimental 
value. In the slump flow test, the highest error value ranges from $0 \%$ to $5.1 \%$. This result shows that the error rate on slump flow testing is still below $5.1 \%$, namely as many as 37 . Meanwhile, the rest of the data experienced an error with a difference from $5.1 \%$ to $11.9 \%$.

Meanwhile, in the T50 test, almost all errors occurred from $0 \%$ to $11.9 \%$, as many as 24 data from a total of 36 experimental data. T50 value test is one method to determine the time for concrete flowing in the slump flow test. Meanwhile, in Fig 5 (c), the V-Funnel test shows that the error rate ranged from $0 \%$ to $13.76 \%$, as many as 42 samples from a total of 60 samples used, while the rest tests obtained error values ranging from $13.76 \%$ to $31.44 \%$. The analysis of fresh properties using the L-Box shows the most widely deviate, ranging from $0 \%$ to $3 \%$, which is 20 from 28 sample data. Meanwhile, testing using the J-ring produces errors ranging from $0 \%$ to $13.43 \%$.

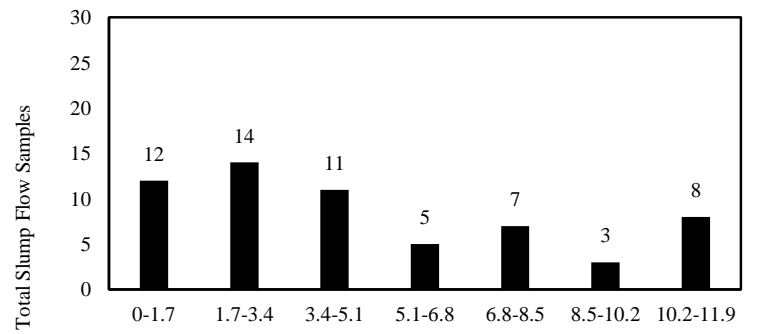

(a)

Error Percentage (\%)

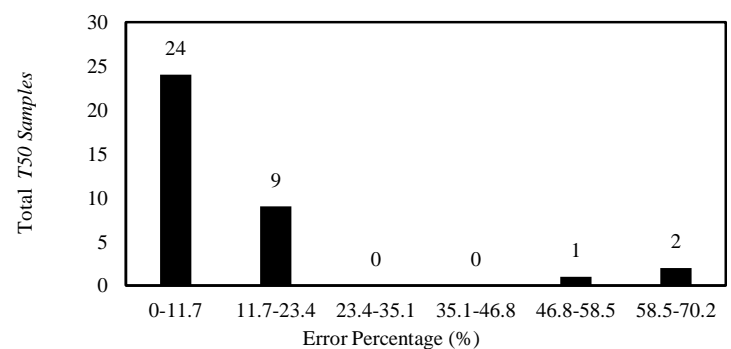

(b)

(c)

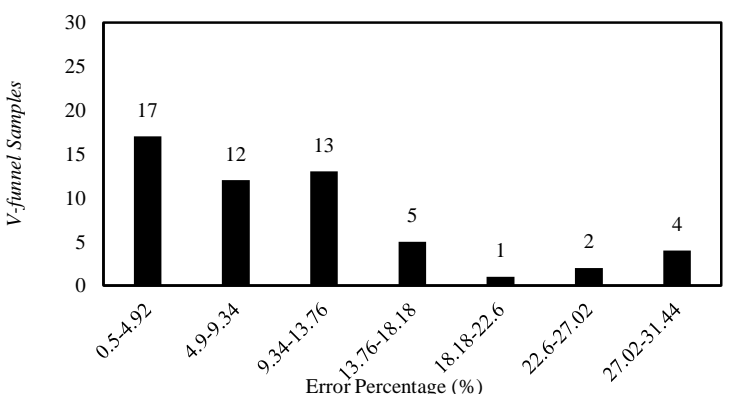

(d)

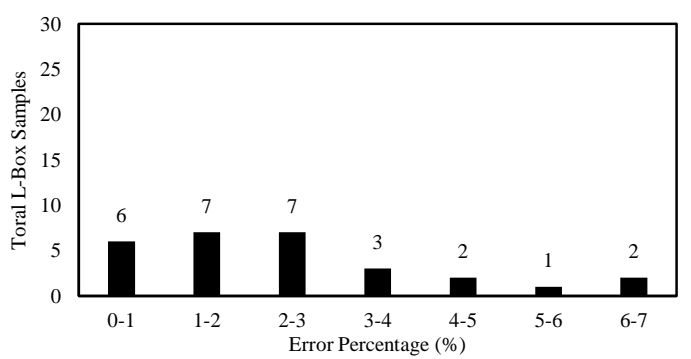

(e)

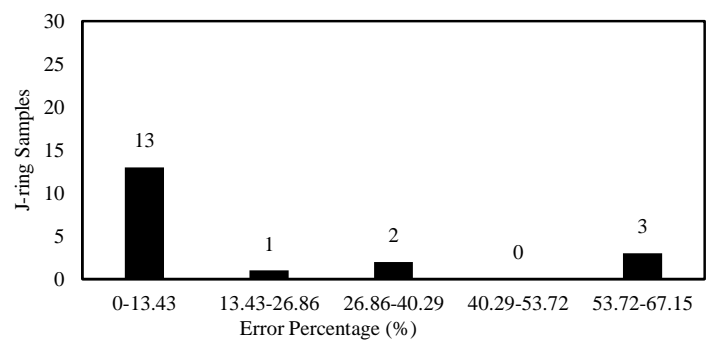

Fig. 5. Total Error (a) Slump flow; (b) T50; (c) V-Funnel; (d) L-Box; (e) J-ring

The prediction on slump-flow testing produces the biggest error, i.e., $11.84 \%$, and the smallest error is $0.07 \%$, with an average error of $5 \%$ thus, the predicted value can approach secondary data. Prediction on the T50 test shows the biggest error, i.e., $70 \%$, and the smallest error is $0 \%$, with an average error of $13.9 \%$. The biggest difference, namely $1.1 \mathrm{~s}$, is relatively small for test data that reaches $7 \mathrm{~s}$, the prediction value is still approaching the test data. Prediction on the vfunnel test produces the biggest error, i.e., $31.43 \%$, and the smallest error is $0.55 \%$, with an average error of $9.78 \%$. The biggest difference is that $3 \mathrm{~s}$ is relatively small for test data, which reaches $15 \mathrm{~s}$; thus, the prediction value is still close to the test data. Prediction on the L-box test produces the biggest error of $6.25 \%$, and the smallest error is $0 \%$ with an average error of $2.27 \%$, the prediction value can approach secondary data. Prediction on the j-ring test produces the biggest error, i.e., $67.4 \%$, and the smallest error is $0 \%$, with an average error of $17.1 \%$. The biggest difference is $5 \mathrm{~mm}$; this difference is relatively small for test data, which reaches $23 \mathrm{~mm}$ so that the predicted value is still getting near to the test data.

\section{Compressive Strength}

The compressive strength prediction of self-compacting concrete using the Mamdani method for fuzzy logic gets an average error value below $10 \%$, i.e., $9.69 \%$. The smallest error value obtained in this study was $0.02 \%$, while the largest error value was $34.42 \%$. The amount of error obtained in data is caused by the data having different characteristics from common data characteristics. The prediction results of the compressive strength of self-compacting concrete using the Mamdani method for fuzzy logic can be seen in Fig 6 (a).

The prediction results of the compressive strength of selfcompacting concrete using the Mamdani method for fuzzy logic show the same results if they have the same input values. Meanwhile, the results of compressive strength on the test get different results even though some of the data's input values are the same. This phenomenon is caused by the compressive strength results obtained from the Mamdani method for fuzzy logic derived from mathematical calculations. Therefore, there is no influence of external factors on the compressive strength test of self-compacting concrete, such as room temperature, curing process, human error. 
The comparison between the test results' compressive strength with fuzzy logic predictions can be seen in Fig 6 (b). Based on these data, it can be seen how much the deviation in each data and the entire testing. It was also shown that the compressive strength prediction results of self-compacting concrete using the Mamdani method for fuzzy logic could obtain the same compressive strength. Meanwhile, the results of the compressive strength test of self-compacting concrete obtained different results. Fig 6 (b) shows a close relationship between the predicted results obtained by the results of previous experiments.

A frequency distribution is used to determine the amount of data in a criterion; it can be seen in Fig 6 (c). Based on the figure, it can be seen that the data with an error value below $10 \%$ reaches 35 data. In error $10-15 \%$, there are 16 data, and errors that reach a percentage above $15 \%$ are only 9 data. This shows that the error rate generated in predicting compressive strength in concrete is still quite high, reaching $10 \%$. However, the relationship between compressive strength in predictions and experiments is quite noticeable. Through this figure, the compressive strength value in the original condition can be predicted if the mix proportion of the selfcompacting concrete is known.

(a)

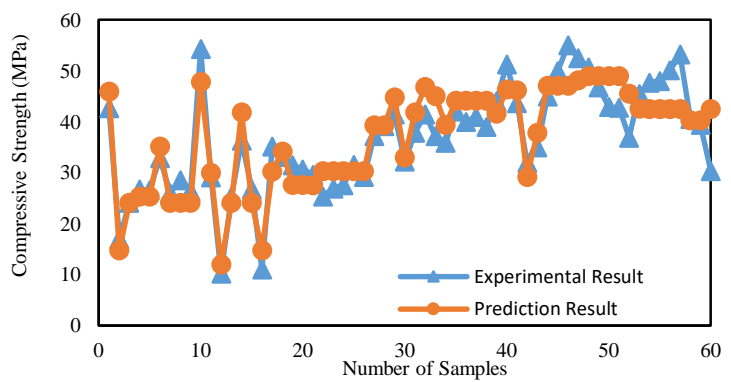

(b)
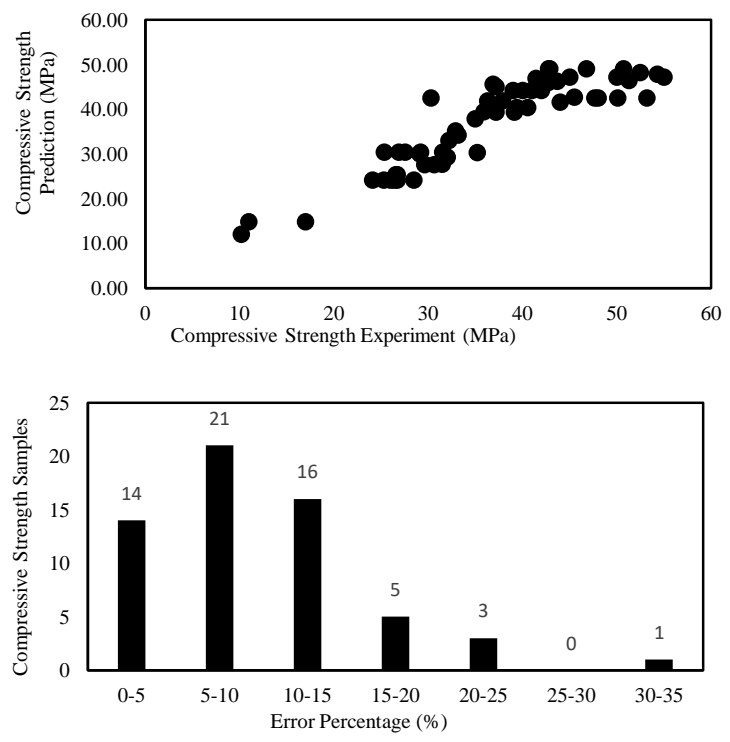

(c)

Fig. 6. (a) Compressive strength result; (b) Relationship between prediction and experiment result on compressive strength; (c) Error distribution

\subsection{Flexural Strength}

Modeling analysis of self-compacting concrete flexural strength using fuzzy logic was compared with flexural strength from laboratory testing that has been done by several researchers with the same amount and material. The limitation of flexural prediction using fuzzy logic is from $3.65 \mathrm{MPa}$ to $7.78 \mathrm{MPa}$. The results of prediction of the value of the fuzzy flexural strength are shown in Fig 7 (a), which is the closest result of 5.54 MPa for the flexural strength of 5.56 MPa for the experimental flexural strength, while the results that are far enough are 6.25 for the fuzzy flexural strength and 5.41 MPa for the experimental flexural strength. The higher fuzzy flexural strength prediction than the experimental flexural strength had an average error percentage of $6.30 \%$, and the lower fuzzy flexural strength had an average percentage error of $5.32 \%$. A comparison of the fuzzy flexural strength and experimental flexural strength results is shown in Fig 7 (b).

The difference in numbers against the experiment's predictive flexural strength and flexural strength is caused by secondary data factors used as a comparison obtained randomly. Thus, each researcher has a different workmanship standard, behavior, and test environment; other factors are error data and the level of accuracy of fuzzy logic. The percentage error is used to determine the accuracy of the prediction of flexural strength obtained from the comparison between the value of the fuzzy flexural strength and secondary data flexural strength testing of self-compacting concrete conducted previously. Based on Fig 7 (c), the smallest error percentage is $0.36 \%$, and the largest is $15.53 \%$. Thus, an average percentage of $5.79 \%$ is obtained, and the standard deviation of the percentage error is $4.20 \%$. The percentage of errors are grouped according to the frequency of distribution. Fig 7 (c) shows the percentage error range of $0.35-2.52 \%$; this percentage shows the most significant number of data contained in the range of 16 data. Meanwhile, in the range of $11.2-13.37 \%$ shows 3 data.

(a)
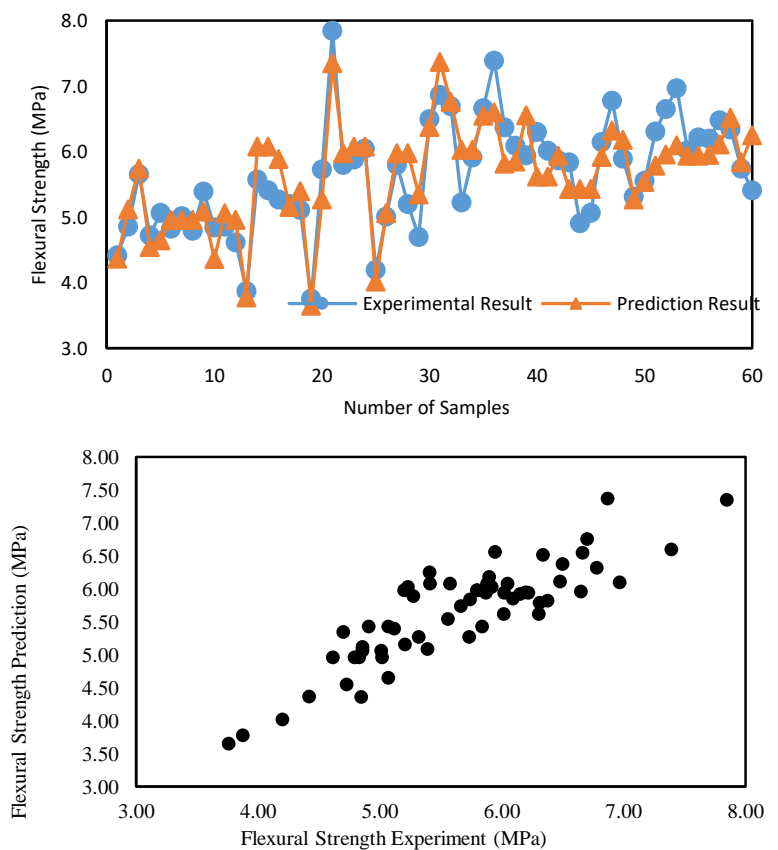

(b) 
(c)

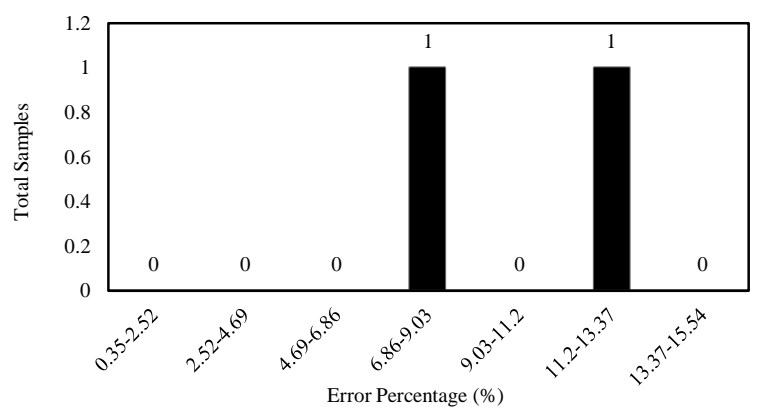

Fig. 7. (a) Flexural strength result; (b) Relationship between prediction and experiment result on flexural strength; (c) Error distribution

\section{CONCLUSION}

In testing the fresh properties of self-compacting concrete, predicted values with varying error rates were obtained. However, the prediction results with experimental results have a fairly close relationship. As well as the error results obtained through the analysis of compressive strength and flexural strength. The prediction of the compressive strength of self-compacting concrete using the Fuzzy method in fuzzy logic has an average error value of $96.9 \%$, with the largest error value of $34.32 \%$, while the smallest error value of $0.02 \%$. Fuzzy logic can predict the compressive strength of self-compacting concrete because it has a relatively small average error value. The flexural strength of self-compacting concrete using fuzzy that has been built can only predict from 3.65 MPa to 7.78 MPa. The prediction of fuzzy logic's flexural strength has the smallest error percentage of $0.36 \%$; the biggest is $15.30 \%$, an average of $5.66 \%$. The data distribution is not too far from the deviation of the error percentage of $3.99 \%$.

\section{ACKNOWLEDGMENT}

The author would like to thank the Institute of Research, Publications, and Community Service of the Universitas Muhammadiyah in providing the grant for this study with the grant number 194/SK-LP3M/XII/2018. The author would also like to thank the Civil Engineering Department, Faculty of Engineering, Universitas Muhammadiyah Yogyakarta, who facilitated this research along with the research team, namely Pradipta Kumara Prabandaru, Nur Ali Maulida, and Jheval Senna Emerald, who has helped a lot until the completion of this research.

\section{REFERENCES}

[1] P. L. Domone, "A review of the hardened mechanical properties of self-compacting concrete," Cement and Concrete Composites, 29(1), pp. 1-12, January 2007.

[2] H. Prayuda., F. Saleh., T. I. Maulana., F. Monika, "Fresh and mechanical properties of self-compacting concrete with coarse aggregate replacement using a waste of oil palm shell, IOP Conference Series: Materials Science and Engineering, The 7th AIC-ICMR, 352, 2018.

[3] N. Bouzoubaa., M. Lachemi, "Self-compacting concrete incorporating high volumes of class $F$ fly ash:
Preliminary result," Cement and Concrete Research, 31(3), pp. 413-420, March 2001.

[4] H. Okamura, "Self-compacting high-performance concrete," Concrete International, 19(7), pp. 50-54, January 1997.

[5] H. Okamura., M. Ouchi, "Self-compacting concrete," Journal of Advanced Concrete Technology, 1(1), pp. 515, April 2003.

[6] N. Su., K. Hsu., H. Chai, "A simple mix design method for self-compacting concrete," Cement and Concrete Research, 31(12), pp. 1799-1870, December 2001.

[7] L. Ferrara., Y. Park., S. P. Shah, "A method for mix design of fiber-reinforced self-compacting concrete, Cement and Concrete Research, 37(6), pp. 957-971, June 2007.

[8] P. Aggarwal., R. Siddique., Y. Aggarwal., S. M. Gupta, "Self-compacting concrete - Procedure for mix design. Leonardo Electronic Journal of Practices and Technologies," 12, pp. 15-24, June 2008.

[9] S. G. Oh., T. Noguchi., F. Tomosawa, "Toward mix design for Rheology Self-compacting concrete," 1st International RILEM Symposium on Self-Compacting Concrete, 1999.

[10] B. Felekoglu., S. Turkel., B. Baradan, "Effect of water/cement ratio on the fresh and hardened properties of self-compacting concrete," Building and Environment, 42(4), pp. 1795-1802, April 2007.

[11] O. Boukendakdji., E. Kadri., S. Kenai, "Effect of granulated blast furnace slag and superplasticizer type on the fresh properties and compressive strength of selfcompacting concrete, Cement and Concrete Composites, 34(4), pp. 583-590, April 2012.

[12] S. Grunewald., J. C. Walraven, "Parameter-study on the influence of steel fibers and coarse aggregate content on the fresh properties of self-compacting concrete," Cement and Concrete Research, 31(12), pp. 1793-1798, December 2001

[13] S. C. Kou., C. S. Poon, "Properties of self-compacting concrete prepared with coarse and fine recycled concrete aggregates," Cement and Concrete Composites, 31(9), pp. 622-627, October 2009.

[14] R. Madandoust., S. Y. Mousavi, "Fresh and hardened properties of self-compacting concrete containing metakaolin," Construction and Building Materials, 35, pp. 752-760, October 2012.

[15] H. Mazaheripour., S. Ghanbarpour, S. H. Mirmoradi., I. Hosseinpour, "The effect of polypropylene fibers on the properties of fresh and hardened lightweight selfcompacting concrete," Construction and Building Materials, 25(1), pp. 351-358, January 2011.

[16] M. Nehdi., H. E. Chabib., M. H. E. Nanggar, "Predicting performance of self-compacting concrete mixtures using artificial neural networks," ACI Materials Journal, 98(5), pp. 394-401, October 2001.

[17] R. Siddique., P. Aggarwal., Y. Aggarwal, "Prediction of compressive strength of self-compacting concrete containing bottom ash using artificial neural networks," Advances in Engineering Software, 42(10), pp. 780-786, October 2011.

[18] H. Mashhadban., S. S, Kutanaei., M. A. Sayarinejad, "Prediction and modeling od mechanical properties in fiber-reinforced self-compacting concrete using particle swarm optimization algorithm and artificial neural network, Construction and Building Materials, 119, pp. 277-287, August 2016.

[19] M. Uysal., H. Tanyildizi, "Predicting the core compressive strength of self-compacting concrete (SCC) mixtures with mineral additive using the artificial neural network," Construction and Building Materials, 25(11), pp. 4105-4111, November 2011

[20] F. M. A. Filho., B. E. Barragan., J. R. Casas., A. L. H. C. E. Debs, "Hardened properties of self-compacting concrete - A statistical approach, Construction, and 
Building Materials, 24(9), pp. 1608-1615, September 2010.

[21] P. G. Asteris, K. G. Kolovos, "Self-compacting concrete strength prediction using surrogate models," Neural Computing and Applications, 31(1), pp. 409-424, January 2019.
[22] J. T Campbell., D. G. Sirmon., M. Schijven, "Fuzzy logic and the market: a configurational approach to investor perceptions of acquisition announcements, Academy of Management Journal, 59, pp. 163-187, 2016. 